\title{
Monitoring managerial efficiency in the performing arts: A regional theatres network perspective
}

\author{
Francisco Marco-Serrano
}

Published online: 23 June 2006

(C) Springer Science + Business Media, LLC 2006

\begin{abstract}
Managerial efficiency within the performing arts programming can be understood as the technical efficiency of transforming the resources cultural managers have available into a determined cultural output. Through this explanation different conceptions on the finished performance product it leads us to select two different output variables (number of performances, and number of attendances). In this way, three different models are considered regarding those conceptual points of view.

Data on the Circuït Teatral Valencià, a Spanish regional theatres network, is used to develop empirically the concept of Managerial Efficiency and set up a framework to allow us to monitor it.
\end{abstract}

Keywords Data envelopment analysis $\cdot$ Managerial efficiency $\cdot$ Performing arts

\section{Introduction}

Since the end of World War II, government has been more and more taking part in the economical and social life becoming an active agent. This has also been true for the cultural sectors, such as the performing arts (i.e. data from Frey and Pommerehne (1991) reveals that the dependence of the German public theatres from the subsidies increased from around $25 \%$ in $1911 / 12$ to almost $85 \%$ in $1985 / 6$ ).

However, this generalised process had a breaking point in the early seventies, when the crises forced governments to reduce and reallocate their budgets, affecting sharply the cultural public expenditure. In fact, we can find this fund-cutting process and the questions that it arose as one of the factors that favoured the starting point of cultural economics (Dupuis, 1993).

Baumol and Bowen's (1966) "Performing Arts. The Economic Dilemma" was published when a framework where discussion on government intervention in cultural production and

F. Marco-Serrano $(\bowtie)$

C.P.3158, Criciúma-SC, 88807-971 (Brazil)

e-mail: fmarco@kproductivity.com 
provision was engaged. Moreover, it allowed to uncover the most dramatic problem in the sector: the difficulties to improve productivity. Therefore, where lack of productivity growth had been substituted by increasing amounts of public funding an alternative had to be found. Efficiency gains are the proposed alternative developed in this paper, and a method that would allow us to monitor its evolution, which is pursued as our main goal.

The structure of this article is as follows. In Section 1, we briefly make some notes on the performing arts production process; the managerial efficiency concept is developed within this framework. In the next section an empirical analysis is carried out with data from the Circuit Teatral Valencià (a Spanish public funded regional theatres network) with the purpose of looking for an efficiency indicator that could allow us and the interested agents (government, fund contributors, or the cultural manager himself/herself) to monitor the managerial efficiency and identify the best management practices within the network. Finally, in Section 3 we conclude and point out future perspectives; some notes for further research are given.

\section{Managerial efficiency in the performing arts}

There is no doubt that, within the cultural sectors, performing arts is the most analysed and peculiar one. In fact, it is an activity that combines the non-repeatability with a high degree of complexity in the production (Rausell, 1999); on the other hand, as stated by Baumol and Bowen (1966), there are few possibilities for productivity improvements. ${ }^{1}$

So far, the production process is quite complicated, consisting of many sub processes, in which several agents participate. Even more, following Mossetto et al. (1993), the kind of analysed institution has to face a qualitative dilemma, dealing with a dual objective: economic and artistic.

Another point to consider would be the selection of the variable for the output. As a first approach, we could choose the number of performances $;^{2}$ however, we would be ignoring the fact that the aim of a performance is to offer the viewers a "cultural experience" (the "educational value" Frey (2000) alludes to, and the "reputational trait") and entertainment. Thus, the performance would only be the intermediate product of a virtual production process where the audience itself would represent the last output. Then, the considered output would be the number of attendances. ${ }^{3}$

A third output definition can be found in Rausell and Carrasco (1999). The variable used in this paper is the attendance rate per capita, in order to analyse the impact of the cultural policy in the performing arts.

Finally, another possibility for defining the output would be to consider the total revenues from the ticket sales (paying attendance $\mathrm{x}$ price). In our analysis, we will be excluding deliberately this variable since our scope is that of public theatres, highly subsidised and

\footnotetext{
${ }^{1}$ However, as noted by Throsby (1994), "although the cost disease will doubtless continue to present the performing arts with difficult problems, it is unlikely to be terminal". Moreover, we can find evidence both on the "Baumol's disease" existence either where it is not present (see Throsby, 1994; Heilbrun, 2003; Luksetich, 2003).

${ }^{2}$ As used in Globerman and Book (1974), Lange et al. (1985), Lange and Luksetich (1993), and Fazioli and Filippini (1997).

3 This variable has been used by Throsby (1977), Gapinski (1980, 1984), Mossetto, Nicoletti, and Ferrarese (1993) and Taalas (1997), as well.
} 
Table 1 Output selection in the literature on performing arts production function

\begin{tabular}{llll}
\hline & \multicolumn{3}{c}{ Output } \\
\cline { 2 - 3 } Works & Performances & Attendances & Attendances p.c. \\
\hline Globerman and Book (1974) & $\mathrm{X}$ & $\mathrm{X}$ & \\
Throsby (1977) & & $\mathrm{X}$ & \\
Gapinski (1980) & & $\mathrm{X}$ & \\
Gapinski (1984) & $\mathrm{X}$ & & \\
Lange et al. (1985) & $\mathrm{X}$ & $\mathrm{X}$ & \\
Lange and Luksetich (1993) & $\mathrm{X}$ & & $\mathrm{X}$ \\
Mossetto et al. (1993) & & $\mathrm{X}$ & 1 \\
Fazioli and Filippini (1997) & & & \\
Taalas (1997) & 4 & 5 & \\
Rausell and Carrasco (1999) & & &
\end{tabular}

Own source.

without any incentives to assume as a target the maximisation on the box collection. ${ }^{4}$

Hence, as we would agree from comparing the different variables used in the literature (see resume in Table 1) there is a clear divergence in the selection of the variable for the output. Such differences in the point of view of the final output for the performing arts process are obviously going to provoke differences in the conclusions or explanations for the analysed framework.

The aim or objectives of the analysis would manifestly be constrained not only by the definition of the output but by the efficiency definition, as well. In Table 2, we can find an outline on four works from the nineties on performing arts production.

Once we have established our production subject, we will need to introduce some basic concepts in order to understand how we are going to monitor this output.

When we try to analyse the performance of a decision maker we always use the concepts of "productivity" and "efficiency" of the production process. We understand "productivity" as the ratio of the products to resources, that is, the quantity of output obtained per unit of employed input. Productivity is determined by a series of factors among which we have: (a) production technology, (b) environment in which the production process develops, and (c) efficiency of the above-mentioned process.

From these dimensions, "efficiency" is considered as a measurement of the comparison between resources and products, and their potential values. Thus, comparisons are established either between the quantities of consumed inputs and the minimum necessary quantity (inputoriented analysis), the obtained output and the maximum achievable output (output-oriented), or both (non-oriented).

We will be using the concept of "technical efficiency". In turn, this one will be able to be decomposed into its elements: "technical pure efficiency" and "scale efficiency".

"Technical Efficiency", understood as the ability to get the most from the available resources, be assumed as the concept of managerial efficiency. ${ }^{5}$

\footnotetext{
${ }^{4}$ According to Frey and Busenhart (1996) this would be explained by the "non-affectation principle", that is, "all expenditures are covered by the public budget, and in return all the revenue goes to the public treasury."

${ }^{5}$ Please note this definition is implicitly assuming an output-oriented conception. From an input-oriented perspective we would be defining it as the ability to use the least amount of resources to obtain a set of given outputs.
} 


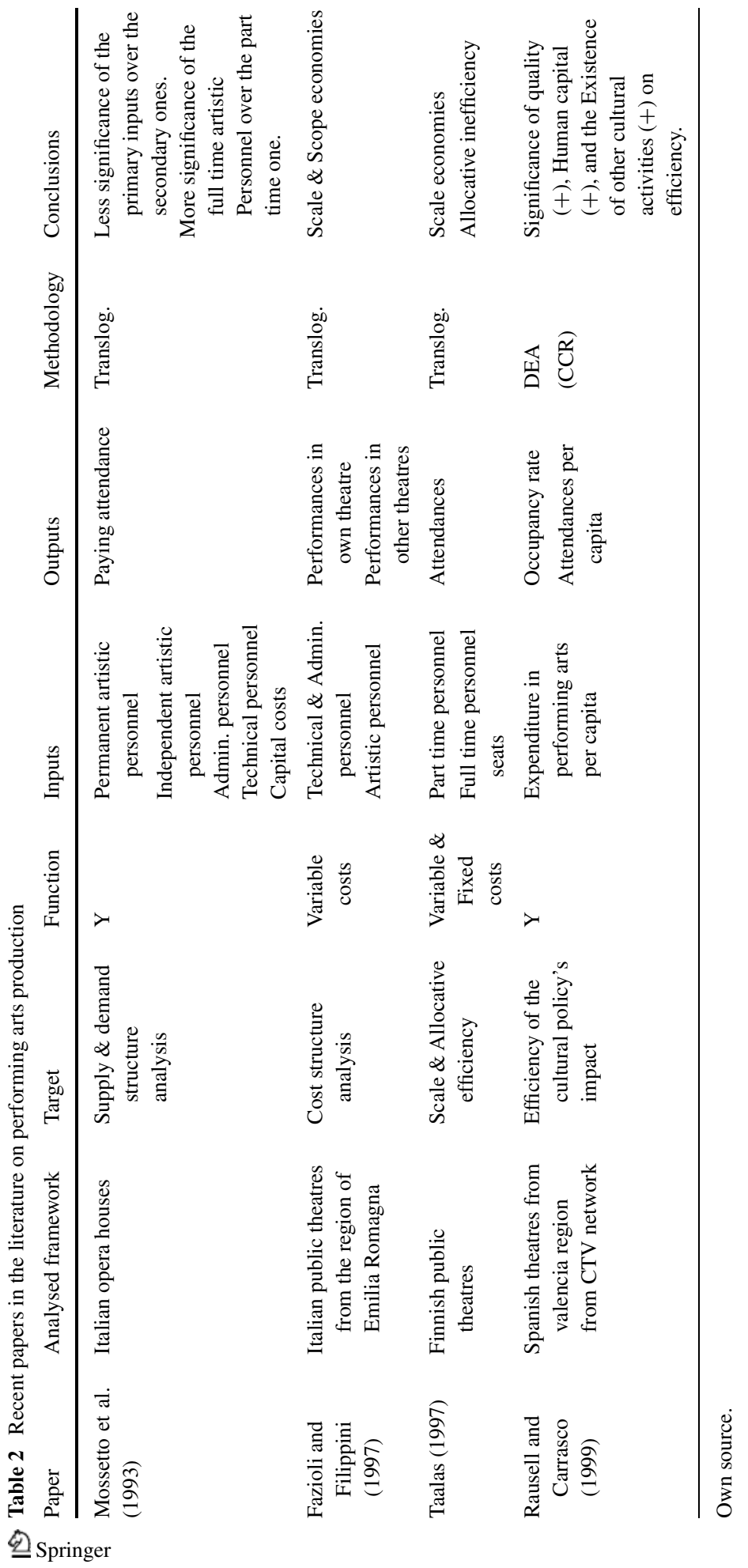


The "scale efficiency" will indicate to us if the manager is operating in the right operational region (i.e. for some managers, the right scale operation could be to program three performances a month, but for some others perhaps only two); leaving the possibility of increasing their performance by de/increasing the inputs/outputs in a determined proportion.

"Technical Pure Efficiency" will be the managerial efficiency on its own; theoretically, it would show us the core of the cultural manager efficiency.

\section{The Circuït Teatral Valencià}

In Spain, just as in some other European countries, the support to cultural activity has been provided mainly by the public sector. This process had its major development in the late eighties coinciding with the decentralisation of some competences, such us cultural policy, to the regional governments.

In the Comunitat Valenciana (Valencia region, which provinces are: Alacant, Castello, and València), many measures were taken in order to encourage cultural consumption, and motivate its production and exhibition. Among them, the Generalitat Valenciana (regional government), through the institution Teatres de la Generalitat (part of the Conselleria de Cultura, regional ministry of culture) as the coordinator, "tried to involve the small and medium villages' city councils for the extension of a performing arts exhibition network that was consolidating regular theatre and dance performances" (Rausell (1999); own translation from Spanish).

This exhibition network (composed of 48 municipalities in 1999), the Circuit Teatral Valencià (CTV), tries to act as a wholesaler towards the artistic companies, incentive the native performing arts companies, and generate pulling effects on expenditure in culture. To accomplish these goals, there are rules, with rights and obligations. The main instrument CTV has available is the subsidies it allocates.

The CTV is managed by means of a General Assembly and a Board, coordinated by the regional ministry of culture. There are four regional commissions, each one with a representative in the Board. Within this structure, each municipality assumes its own decisionmaking, driven by both the cultural manager (cultural technician) and the cultural politician, and partly financed by CTV grants. In this way, the CTV could be considered as a consultant, coordinator, and sponsor of the municipal theatrical programming process.

Within this empirical framework an analysis of the managerial efficiency of every municipal cultural responsible will be assessed as a tool for a further monitoring and benchmarking process.

\subsection{Methodology}

With the intention of being consistent with microeconomic production theory and being conscious of the existence of inefficiencies in the performing arts, we have chosen for our analytical purposes a frontier technique.

Among the different solutions, it has been decided to use the non-parametric technique Data Envelopment Analysis (DEA) since there is no need to explicitly specify a mathematical form for the production function and it has proven to be useful in uncovering relationships that remain hidden for other methodologies. Furthermore, it is capable of handling multiple inputs and outputs, and the sources of inefficiency can be analysed and quantified for every evaluated unit. 
Fig. 1 Output-oriented primal DEA-CCR model

$$
\begin{array}{rr}
\max _{\phi, \lambda, s^{+}, s^{-}} & \mathrm{z}_{\mathrm{o}}=\phi+\varepsilon \overrightarrow{1} \mathrm{~s}^{+}+\varepsilon \overrightarrow{1} \mathrm{~s}^{-} \\
\text {s.t.: } \quad \phi \mathrm{Y}_{\mathrm{o}}-\mathrm{Y} \lambda+\mathrm{s}^{+}=0 \\
\mathrm{X} \lambda+\mathrm{s}^{-}=\mathrm{X}_{\mathrm{o}} \\
\lambda, \mathrm{s}^{+}, \mathrm{s}^{-} \geq 0
\end{array}
$$

Fig. 2 BCC restriction

In the DEA methodology, formerly developed by Charnes, Cooper, and Rhodes (1978), efficiency is defined as a weighted sum of outputs to a weighted sum of inputs, where the weights structure is calculated by means of mathematical programming and constant returns to scale are assumed (see Fig. 1). We run an output-oriented DEA model since we are assuming behaviour that is trying to maximise the results of the performing arts programming process.

$Y$ and $X$ are the output $(s \times n)$ and input $(r \times n)$ matrix respectively, $n$ being the number of decision uits; $\phi_{j}$ the augmentation scalar, $\varepsilon$ is an infinitesimal constant term and $\mathbf{1}$ is a unitary vector; 1 is the vector of coefficients that conform the linear combination to which the DMU in evaluation is compared (reference group), and $s^{+}$and $s^{-}$are the slacks. If we add the restriction shown in Fig. 2, we would be considering a model with variable returns to scale (BBC model).

Technical efficiency will be obtained from a DEA-CCR ${ }_{\mathrm{O}}$ model $\left(\mathrm{TE}=z_{0}-\mathrm{CCR}\right)$; technical pure efficiency will be calculated from a DEA-BCC $C_{O}$ model (TPE $=z_{0}-\mathrm{BCC}$ ). Therefore, considering a multiplicative relationship between the technical pure and scale efficiencies (SE), the calculation of the scale efficiency is straightforward (SE = TE/TPE).

The value taken by these scores will allow us to confirm if the evaluated manager is being efficient (unitary value) or if he or she could increase his/her performance efficiency by a determined percentage $\left(z_{o}-1\right) \%$, at the same time we will be analysing if he or she is operating at an efficient scale.

\subsection{The data}

The data we will use is the one from the quantitative aggregated variables for each municipality extracted from the database the Coordinators of the CTV manage (sum, average and standard deviation are shown in Table 3). The selected variables are AFORO (venue capacity: number of seats on theatres or estimated capacity when outdoors; this input can be considered as variable in the short term since the cultural manager can increase the capacity by means of programming more than once a week, for example), OBRAS (number of different performed plays), CACHE (total paid to the performing company in constant Spanish Pesetas (Base, 1992), adjusted using the price index for culture \& entertainment from the INE (Spanish National Statistics Agency); it is used as a proxy for quality), FUNCION (number of performances), ESPECT (number of attendances), SUBVEN (amount subsidised by the CTV, again in 1992 constant Spanish Pesetas).

\subsection{Model selection}

The underlying production function we will assume is going to have three different specifications, as shown in Table 4. The first two models will consider a single target for the 


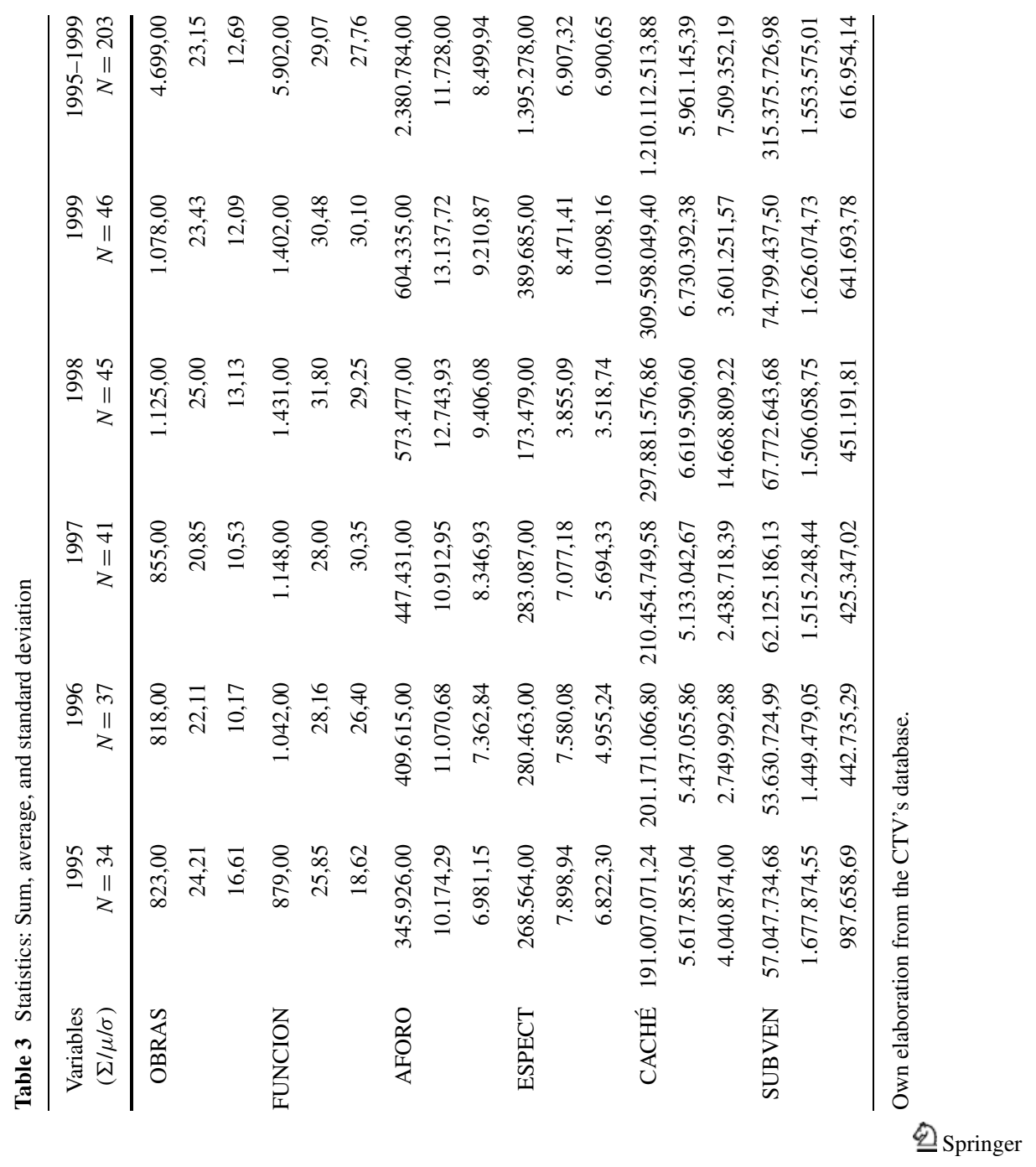


Table 4 Production models specification*

*I: Input, O: Output.

\begin{tabular}{llcl}
\hline & \multicolumn{3}{c}{ Model } \\
\cline { 2 - 4 } Variables & 1 & 2 & 3 \\
\hline AFORO & $\mathrm{I}$ & $\mathrm{I}$ & $\mathrm{I}$ \\
OBRAS & $\mathrm{I}$ & $\mathrm{I}$ & $\mathrm{I}$ \\
CACHE & $\mathrm{I}$ & $\mathrm{I}$ & $\mathrm{I}$ \\
SUBVEN & $\mathrm{I}$ & $\mathrm{I}$ & $\mathrm{I}$ \\
FUNCION & $\mathrm{O}$ & - & $\mathrm{O}$ \\
ESPECT & - & $\mathrm{O}$ & $\mathrm{O}$ \\
\hline
\end{tabular}

performing arts policy (maximise the number of plays, or the educational value), whereas the third one will consist of a mixed target. ${ }^{6}$

We will proceed to evaluate the models for the complete period, year by year (from 1995 to 1999), and the whole panel (all municipalities for the 5 years).

From their results we will analyse if the selected variable for the output affects the conclusions that the obtained results would lead us to.

\subsection{Results}

Having calculated the relative efficiencies (using EMS v.1.3 software; Scheel (2000)) for the different analysed years and the three alternative specifications, descriptive statistics (weighted average and variation coefficient) are shown in Table 5.

In Graphs 1 to 3 the average efficiency evolution for the five analysed years is shown. From them we can notice the technical efficiency has deteriorated (the calculated indexes of efficiency move away from the unit), that is, given the total resources which the different cultural agents have relied on, the gap between the potential output and the effective one has gradually increased.

The efficiency scores calculated by means of model 1 increase period-to-period, managing to place its average level in 2.40 (the number of performances should be on average more than double it is). As for model 2, though in the beginning an improvement pattern can be seen until 1997 (the efficiency scores have a negative trend) it ends up in a level worst than the initial one (3.21 in 1999 against the former 2.47). When the "mixed target" model is taken into account the same increasing inefficiency trend is noticed. ${ }^{7}$

Before we try to explain this trend, we should be made aware of the drawbacks of the chosen technique, such as the size sample bias and a low tolerance to outliers. As the sample is changing through the time line (new municipalities adhere to the network) any change in the overall efficiency should be looked at cautiously since it could be an artificial effect derived from either different sample sizes (see Zhang and Bartels, 1998) either the existence of extreme values.

Considering these aspects, we have to try to analyse which are the real reasons for the increasing inefficiencies. A first explanation for the increase in the average inefficiency scores

\footnotetext{
${ }^{6}$ Although it would be interesting to analyse and contrast a third single target (related to the impact of the performing arts policy), the lack of consistent population data at a municipal level in order to calculate the third output variable (attendance per inhabitant) makes us take it out from this analysis.

${ }^{7}$ It would be easy to affirm that the "mixed target" model reflects better efficiency results. However, we do not have to forget that these results could improve just by means of increasing the number of variable-outputs, as it is the case.
} 
Table 5 Average and variation coefficient for the efficiency scores

\begin{tabular}{|c|c|c|c|c|c|c|}
\hline \multirow[b]{2}{*}{ Year } & \multicolumn{2}{|c|}{ Model 1} & \multicolumn{2}{|c|}{ Model 2} & \multicolumn{2}{|c|}{ Model 3} \\
\hline & Average & $\mathrm{VC}$ & Average & $\mathrm{VC}$ & Average & $\mathrm{VC}$ \\
\hline \multicolumn{7}{|c|}{ Technical efficiency (TE) } \\
\hline 1995 & 1.1716 & 0.1153 & 2.4710 & 0.4534 & 1.1384 & 0.1076 \\
\hline 1996 & 1.9852 & 0.3638 & 2.4552 & 0.5101 & 1.6336 & 0.3441 \\
\hline 1997 & 1.9528 & 0.4343 & 1.7755 & 0.3335 & 1.5429 & 0.2917 \\
\hline 1998 & 1.9627 & 0.4222 & 2.1984 & 0.7360 & 1.5424 & 0.3741 \\
\hline 1999 & 2.3973 & 0.3566 & 3.2138 & 0.3594 & 1.8780 & 0.3155 \\
\hline $95-99$ & 2.3219 & 0.4029 & 4.1060 & 0.7136 & 1.9216 & 0.3596 \\
\hline \multicolumn{7}{|c|}{ Pure technical efficiency (TPE) } \\
\hline 1995 & 1.1388 & 0.1109 & 2.0777 & 0.3975 & 1.1156 & 0.1012 \\
\hline 1996 & 1.8155 & 0.3734 & 1.9748 & 0.3753 & 1.4946 & 0.2939 \\
\hline 1997 & 1.5809 & 0.3918 & 1.5117 & 0.3262 & 1.3082 & 0.2632 \\
\hline 1998 & 1.6441 & 0.3821 & 1.8171 & 0.7976 & 1.3478 & 0.3222 \\
\hline 1999 & 2.1075 & 0.3787 & 3.0789 & 0.3750 & 1.7526 & 0.3352 \\
\hline $95-99$ & 2.2016 & 0.4027 & 3.8327 & 0.7342 & 1.8474 & 0.3502 \\
\hline \multicolumn{7}{|c|}{ Scale efficiency (SE) } \\
\hline 1995 & 1.0289 & 0.0405 & 1.2086 & 0.2861 & 1.0204 & 0.0363 \\
\hline 1996 & 1.1363 & 0.3882 & 1.3589 & 0.8552 & 1.1213 & 0.3949 \\
\hline 1997 & 1.3027 & 0.5022 & 1.2066 & 0.3074 & 1.2058 & 0.3024 \\
\hline 1998 & 1.2043 & 0.2606 & 1.2832 & 0.3838 & 1.1500 & 0.2248 \\
\hline 1999 & 1.1951 & 0.4196 & 1.0625 & 0.1286 & 1.0830 & 0.0856 \\
\hline $95-99$ & 1.0770 & 0.3260 & 1.1357 & 0.6417 & 1.0506 & 0.2488 \\
\hline
\end{tabular}

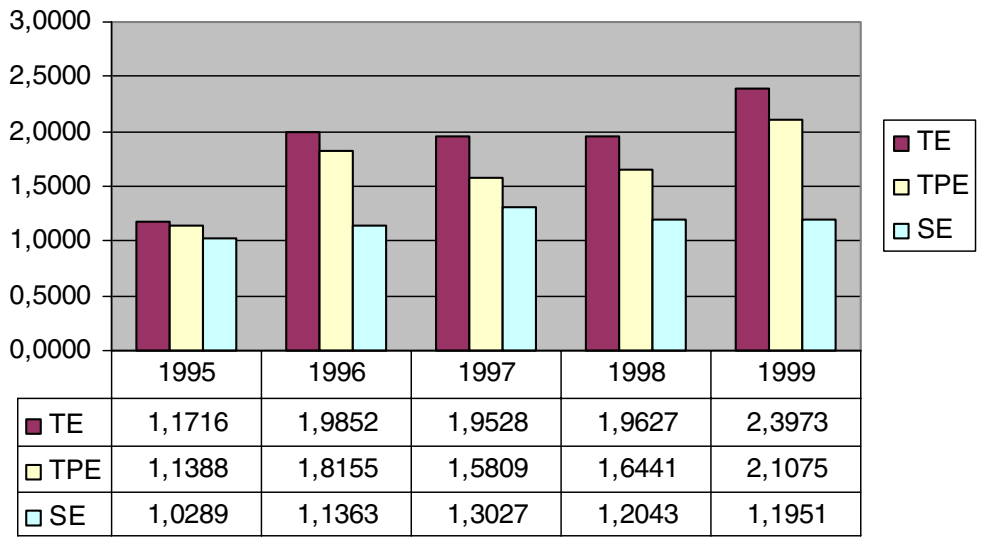

Graph 1 Average efficiency evolution-Model 1 


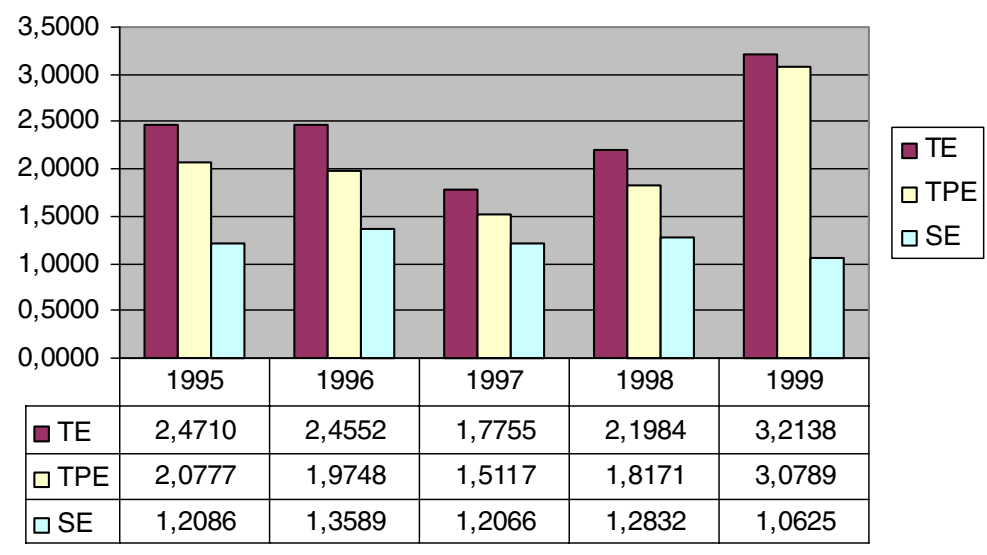

Graph 2 Average efficiency evolution-Model 2

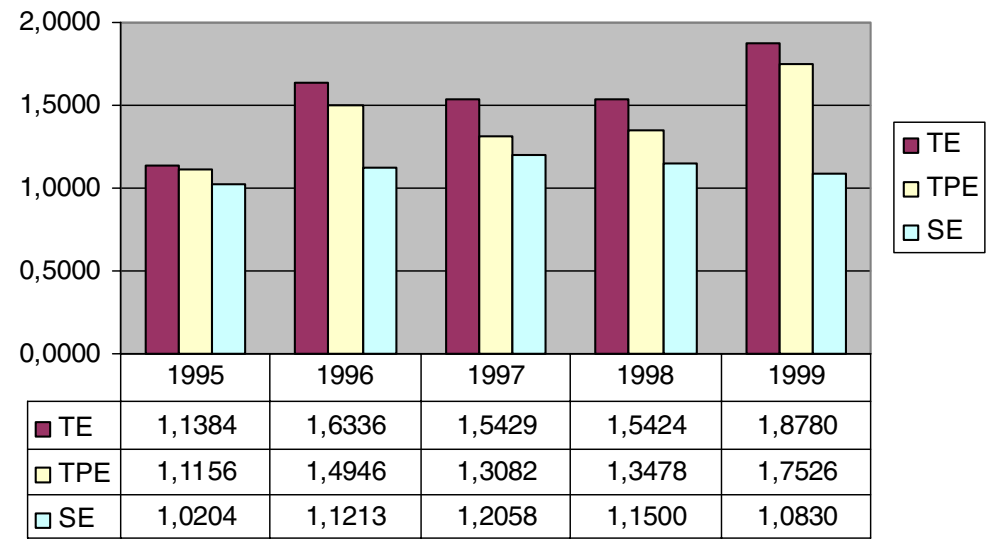

Graph 3 Average efficiency evolution-Model 3

would indicate that with the successive incorporation of different municipalities to the CTV the resources have been employed less efficiently for the attainment of more performances and/or attendances. To a municipal level the results are heterogeneous enough, as the high values of the variation coefficients indicate; in the majority of the cases they overcome $35 \%$, managing to take values superior to $50 \%$.

The decline in the efficiency, nevertheless, not only can be provoked by the simple incorporation of municipalities to the CTV that bring it over to a saturation point, but also for the fact that the new municipalities, for diverse reasons, have a more inefficient behaviour than the average of the previous members. So that, in spite of not affecting the relative efficiency of these it does produce a decrease in the average efficiency level, as well as increasing heterogeneity.

The opposite case, the incorporation of the most efficient units, it would provoke individual changes, reducing the efficiency (increasing the scores), but with an indeterminate effect on the dispersion of the individual efficiencies. In all cases, bearing in mind such municipalities are not to be considered extreme values. 
Table 6 Distribution of the municipalities regarding incorporation and technical pure efficiency

\begin{tabular}{|c|c|c|c|c|c|c|c|c|c|c|c|c|c|c|c|c|}
\hline \multirow[b]{2}{*}{ Score } & \multirow[b]{2}{*}{ New } & \multicolumn{5}{|c|}{ Model 1} & \multicolumn{5}{|c|}{ Model 2} & \multicolumn{5}{|c|}{ Model 3} \\
\hline & & 95 & 96 & 97 & 98 & 99 & 95 & 96 & 97 & 98 & 99 & 95 & 96 & 97 & 98 & 99 \\
\hline \multirow[t]{2}{*}{$z=1$} & Yes & 12 & 1 & 2 & 1 & 1 & 6 & 1 & 2 & 2 & 1 & 13 & 1 & 2 & 2 & 1 \\
\hline & No & & 4 & 9 & 10 & 2 & & 4 & 7 & 13 & 2 & & 7 & 13 & 18 & 3 \\
\hline \multirow[t]{2}{*}{$1<z \leq 2$} & Yes & 22 & 1 & 2 & 3 & 0 & 11 & 2 & 2 & 1 & 0 & 21 & 2 & 3 & 2 & 0 \\
\hline & No & & 17 & 18 & 18 & 22 & & 13 & 26 & 18 & 5 & & 23 & 22 & 18 & 25 \\
\hline \multirow[t]{2}{*}{$z>2$} & Yes & 0 & 1 & 1 & 1 & 0 & 17 & 0 & 1 & 2 & 0 & 0 & 0 & 0 & 1 & 0 \\
\hline & No & & 13 & 9 & 12 & 21 & & 17 & 22 & 9 & 38 & & 4 & 1 & 4 & 17 \\
\hline
\end{tabular}

If we look at the average efficiency scores for the complete panel (common frontier) we can notice the value is always kept above the average yearly values except for the last year; in fact, 1999 is the worst year in efficiency terms, that is, the municipalities conforming the CTV this year have a behaviour much less efficient.

From the decomposition of the technical efficiency in its two components (ETP and ES) we can deduct that this worsening in the efficiency of the studied relation of cultural transformation derives for the most part from the technical pure efficiency, in other way, the scale efficiency is kept stable. Even more, the fact that the first model always takes values near to the unit indicates to us that, in average, the components of the CTV operate in a production scale with constant returns. Anyhow, previous analyses have identified economies of scale in the performing arts sector in different countries and regions for what, even taking values near to one, we do not deny totally the existence of this type of economies in the considered production process.

In fact, in the second considered specification we can realise the progressive approximation of this index to an unitary value, indicating that (for the output attendance) the CTV has been coming closer to a production scale in which there are not scale economies (possibility that the product increases in a major or minor proportion to which the resources increase); therefore, in this case the final worsening in the efficiency is practically totally imputable to the technical pure efficiency, to the cultural manager.

We can see the distribution of the municipalities with regards to their incorporation to the network and technical (pure) efficiency in Table 6 to help us analyse which process is having more importance in determining the downward trend for the efficiency.

From the information displayed in this table, we are able to affirm that both previously exposed processes are being occurring. On one hand, year after year municipalities that are more efficient join the CTV, altering the global structure and reducing this way the level of efficiency. On the other hand, inefficient ones join also, those are in some cases very inefficient, provoking an increase of the inefficiency by themselves (without affecting directly the efficiency of the rest of municipalities).

Besides that, an effect that reinforces this process of worsening the efficiency in the relation of cultural transformation that has been observed is the fact that in 1999 the number of efficient $(z=1)$ municipalities diminishes drastically, and simultaneously the number of very inefficient $(z>2)$ increases. This is a widespread process that should be thoroughly analysed, provided that it implies that the only three efficient municipalities are (excessively) better than the rest.

A common feature to all models, though higher in the second one, is the high average inefficiency level. Values that in certain moments exceed 2 would indicate that to be efficient 
should be capable of, with the same resources, doubling the obtained production; this reaction would prevent in a competitive environment the survival of the analysed unit. Nevertheless, we do not have to forget the context in which we move; first, it is a matter of a subsidised theatrical network which units are public entities of the local area. On the other hand, the agents will tend to try to satisfy their artistic preferences; simultaneously they will be determined by the municipal political framework. Of this triangle, CTV-Cultural Manager-Politician, sources of inefficiency will arise. Even more, as noted in Rausell and Carrasco (1999), another factor that will affect the efficiency will be the characteristics of the demand; we are considering small and medium municipalities, linked to a demographic structure, of cultural education and, definitively, of preferences that will reverberate on the relation of theatrical transformation.

The conjunction of all these factors, and an in depth analysis into how it affects every local authority, might help us to understand the appearance of so high inefficiency levels, provoked by the existence of a series of municipalities standing widely out the rest.

The trend that has been revealed with the obtained results is clearly defined whatever the variable output. Anyway, if we want to evaluate this fact for individual performances we should carry out a robustness analysis. We can consider a model is robust if when we evaluate different alternative specifications and variables slight changes in the selected variable list is not significantly modifying the conclusions that the results of the DEA model have exposed. Therefore, we will be able to test if the obtained efficiency results are variable-dependant (Nunamaker, 1985).

In that way, we defined three different models attached to two different targets of the municipal performing arts cultural policy: maximise the number of performances (model 1), the number of people that attend to them (model 2), or a "mixed target" (model 3). If our aim was to analyse the robustness of the efficiency scores, the correlation coefficients are our analysis instrument.

In Table 7, Pearson coefficients for the different managerial efficiency measures are shown, as well as Kendall's Tau coefficient for the rankings. It is indicated with one asterisk when the coefficient has statistical significance at a level of $5 \%$, two for $1 \%$.

In order to admit the robustness of the efficiency scores we should appreciate that a stable relationship exists between the results of all three models; this stability would come shown by high values of the correlation coefficients, along with reasonable statistical significance levels. Then, high values would show that either the relative efficiency either the ranking we can get from those efficiency scores for the different cultural managers is not variable specific.

Table 7 Correlation coefficients for the scores and ranking technical efficiency

\begin{tabular}{|c|c|c|c|c|c|c|}
\hline & 1995 & 1996 & 1997 & 1998 & 1999 & Panel \\
\hline \multicolumn{7}{|l|}{ TE scores } \\
\hline Models 1 \& 2 & 0.201 & $0.456^{* *}$ & $0.468^{* *}$ & 0.115 & -0.013 & 0.098 \\
\hline Models $1 \& 3$ & $0.898^{* *}$ & $0.815^{* *}$ & $0.782^{* *}$ & $0.683^{* *}$ & $0.758^{* *}$ & $0.856^{* *}$ \\
\hline Models 2 \& 3 & $0.375^{*}$ & $0.820^{* *}$ & $0.844^{* *}$ & $0.460^{* *}$ & $0.427^{* *}$ & $0.353^{* *}$ \\
\hline \multicolumn{7}{|l|}{ TE ranks } \\
\hline Models $1 \& 2$ & $0.251^{*}$ & $0.282^{*}$ & $0.343^{* *}$ & 0.057 & 0.005 & $0.160^{* *}$ \\
\hline Models $1 \& 3$ & $0.773^{* *}$ & $0.703^{* *}$ & $0.638^{* *}$ & $0.595^{* *}$ & $0.682^{* *}$ & $0.745^{* *}$ \\
\hline Models $2 \& 3$ & $0.425^{* *}$ & $0.576^{* *}$ & $0.700^{* *}$ & $0.460 * *$ & $0.305^{* *}$ & $0.409^{* *}$ \\
\hline
\end{tabular}


After checking the above coefficients, we could maintain with difficulty the robustness hypothesis. In general, there are no strong correlations between the first two models of the analysed years neither for the efficiency scores neither for the rankings. In fact, only in the results for 1996 and 1997 we can find significant relationships, although always with values below 0.50 .

With reference to the "mixed target" model, as expected since it includes both single objectives, it correlations to model 1 and 2 . However, the fact that it achieves much higher values with model 1 results is showing us that the target of maximising performances overweights the second target ("cultural-educational value" maximisation).

\section{Final conclusions}

Productivity improvements will require a favourable environment, as well as a simultaneous increasing technical progress and efficiency rise. Therefore, CTV will act like a true catalyst when canalising efforts towards the improvement of the environment. The organization, next to other actors in this triangle, will try to improve the cultural transformation relationship (i.e. managerial education), which will have global effects in the middle and long term. However, when considering the efficiency component, it will exclusively depend on the capability and ability of the municipal cultural manager.

The cultural manager will try to optimise his/her available resources in order to achieve the targets the performing arts programming has been devised to. Any deviations with respect to the maximum output will be considered inefficient behaviour from the managerial point of view. Consequently, any information the cultural manager can receive with regards to the performing arts programming efficiency should be received as a powerful benchmarking tool.

At a CTV level we have found decreasing trends for the managerial efficiency, caused by the progressive municipalities incorporation into the network, either by the existence of a saturation point, or because these incorporations drastically affect the structure of the cultural production frontier. Of course, since further individual analysis has been excluded from this article these considerations could be considered mere speculations based on descriptive data; a more detailed analysis of the input-output weights and the nature of the individual municipalities has been relegated to future research.

In order to evaluate the efficiency it has to be considered that the target to achieve will affect the specification of our production process. That is the reason why we will have to test if the efficiency model will be sensible to the variable linked to the selected target. In this sense, the analysis has shown us a clear divergence in the results obtained by means of the two main different output-targets. It indicates that the efficiency model will vary with respect to the election of output. That is, we would not have to make comparisons between the indexes of efficiency of municipalities with different targets; moreover, the segmentation would have to take place in the calculation of these indexes, since we would be assessing different cultural transformation frontiers. Even more, when a "mixed target" model is calculated the variable associated to the first model (performances) overweights the one used in the second one (attendance).

Then, future analysis would have to be directed towards the search of the (apparent) target pursued by each municipality, so that we could be able to diagnose the technical status in the cultural production function associated with its target in relation to the rest of municipalities with the same target. Once achieving this goal, we would be finally ready to look for that simple index that would inform us periodically into the advances of the municipal manager in the achievement of the target. 
Acknowledgments The author gratefully acknowledges the Coordination of the "Circuït Teatral Valencià" for providing the data and the interest shown for the project. He also wishes to thank the patience and help of J.M.Pastor in tutoring a previous dissertation, as well as the comments from Pau Rausell, both from the Universitat de València (Spain). This article has benefited from the comments of two anonymous referees.

\section{References}

Ali, A.I. and L.M. Seiford. (1993). “The Mathematical Programming Approach to Efficiency Analysis.” In H.O. En Fried, C.A.K. Lovell, and S.S. Schmidt (eds.), The Measurement of Productive Efficiency: Techniques and Applications. Oxford University Press, Oxford, NY.

Banker, R.D., A. Charnes, and W.W. Cooper. (1984). "Some Models for Estimating Technical and Scale Inefficiencies in Data Envelopment Analysis.” Management Science, 30, 1078-1092.

Baumol, W.J. and W.G. Bowen. (1966). Performing Arts. The Economic Dilemma. Twentieth Century Fund, New York.

Charnes, A., W.W. Cooper, and E. Rhodes. (1978). "Measuring the Efficiency of Decision Making Units." European Journal of Operational Research, 2, 429-444.

Charnes, A., W.W. Cooper, A.Y. Lewin, R.C. Morey, and J.J. Rousseau. (1985). "Sensitivity and Stability Analysis in DEA." Annals of Operations Research, 2, 139-156.

Dupuis, X. (1993). The European Approach to Cultural Economics. FEDAEC. Ed.Il Mulino.

Fazioli, R. and M. Filippini. (1997). "Cost Structure and Product Mix of Local Public Theatres.” Journal of Cultural Economics, 21, 77-86.

Felton, M.V. (1994-5). "Evidence of the Existence of the Cost Disease in the Performing Arts." Journal of Cultural Economics, 18(4), 301-312.

Frey, B. (2000). La Economía del Arte. Colección Estudios Económicos, Núm.18. Servicio de Estudios de "la Caixa", Barcelona.

Frey, B.S. and I. Busenhart. (1996). "Special Exhibitions and Festivals; Culture's Booming Path to Glory." In V.A. Ginsburgh and P. Menger. (eds.), Economics of the Arts. Selected Essays. Elsevier, Amsterdam.

Frey, B.S. and W.W. Pommerehne. (1991). Muse e Mercati: Indagine Sull'economia dell'arte. Il Mulino, Bologna.

Fried, H.O., C.A.K. Lovell, and S.S. Schmidt. (eds.), (1993). The Measurement of Productive Efficiency: Techniques and Applications. Oxford University Press, Oxford, NY.

Gapinski, J.H. (1980). “The Production of Culture.” Review of Economics and Statistics, 62, 578-586.

Gapinski, J.H. (1984). “The Economics of Performing Shakespeare.” American Economic Review, 74, 458466.

Globerman, S. and S.H. Book. (1974). "Statistical Cost Functions for Performing Arts Organizations.” Southern Economic Journal, 40, 668-671.

Grosskopf, S. (1993). "Efficiency and Productivity.” In H.O. En Fried, C.A.K. Lovell, Schmidt, S.S. (eds.), The Measurement of Productive Efficiency: Techniques and Applications. Oxford University Press, Oxford, NY.

Heilbrun, J. (2003). “Baumol's Cost Disease.” In R. Towse (eds.), A Handbook of Cultural Economics. Edward Elgar, Cheltenham, UK/Northampton, MA, USA.

Lange, M., J. Bullard, W. Luksetich, and P. Jacobs. (1985). “Cost Functions for Symphony Orchestras.” Journal of Cultural Economics, 9, 71-85.

Lange, M. and W. Luksetich. (1993). "The Cost of Producing Symphony Orchestra Services." Journal of Cultural Economics, 17(1), 1-15.

Lehman, E.V. (1995). "Symphony Orchestra Organizations: Development of the Literature Since 1960." Harmony. Forum of the Symphony Orchestra Institute, 1, 35-54.

Luksetich, W.A. (2003). "Orchestras. In R. Towse (eds.), A Handbook of Cultural Economics. Edward Elgar, Cheltenham, UK/Northampton, MA, USA.

Marco-Serrano, F. (2001). Análisis de Eficiencia en el Sector de las Artes Escénicas: El Caso del 'Circuït Teatral Valencià'. (1995-1999). 'Diploma d'Estudis Avançats' Dissertation. Departament d'Anàlisi Econòmica, Universitat de València.

Mossetto, G., C. Nicoletti, and P. Ferrarese. (1993). The Economics of Opera Houses. University of Venice, Mimeo.

Nunamaker, T. (1985). "Using Data Envelopment Analysis to Measure the Efficiency of Non-profit Organizations: A Critical Evaluation.” Managerial and Decision Economics, 6, 50-58.

Rausell, P. (1999). Políticas y Sectores Culturales en la Comunidad Valenciana. Tirant lo Blanch-Universitat de València, València. 
Rausell, P. and S. Carrasco. (1999). Analysis of the Relative Efficiencies of the Theatres of the "Circuit Teatral Valencià.” A political Economy Approach. Proceedings of the 5th International Conference on Arts \& Cultural Management (AIMAC), Helsinki, June 13-17.

Schell, H. (2000). “EMS: Efficiency Measurement System User's Manual. Version 1.3.” Universität Dortmund.

Scitovsky, T. (1972). "What's Wrong with the Arts is What's Wrong with Society." American Economic Review, 62, 62-69.

Taalas, M. (1997). "Generalised Cost Functions for Producers of Performing Arts-Allocative Inefficiencies and Scale Economies in Theatres.” Journal of Cultural Economics, 21, 335-353.

Throsby, D. (1977). "Production and Cost Relationships in the Supply of Performing Arts Services." In K. Tucker (ed.), Economics of the Australian Services Sector. Groom Helm, London.

Throsby, D. (1994). "The Production and Consumption of the Arts: A View of Cultural Economics." Journal of Economic Literature, XXXII, 1-29.

Towse, R. (ed), (2003), A handbook of cultural economics. Edward Elgar, Cheltenham, UK/Northampton, MA, USA.

Valdmanis, V. (1992). "Sensitivity Analysis for DEA Models. An Empirical Example Using Public vs. NFP Hospitals." Journal of Public Economics, 48, 185-205.

Zhang, Y. and R. Bartels. (1998). "The Effect of Sample Size on the Mean Efficiency in DEA with an Application to Electricity Distribution in Australia, Sweden and New Zealand." Journal of Productivity Analysis, 9(3), 187-204. 